\title{
T-Lymphocyte Proliferation Index
}

National Cancer Institute

\section{Source}

National Cancer Institute. T-Lymphocyte Proliferation Index. NCI Thesaurus. Code C161337.

A relative measurement (ratio or percentage) of T-lymphocyte proliferation due to stimulation by an antigen of interest to a non-stimulated T-lymphocyte proliferation control. 